\title{
Cortical development of AMPA receptor trafficking proteins
}

\author{
Kathryn M. Murphy ${ }^{1,2 *}$, Lilia Tcharnaia ${ }^{1}$, Simon P. Beshara ${ }^{1}$ and David G. Jones ${ }^{3}$ \\ ${ }^{1}$ McMaster Integrative Neuroscience Discovery and Study Program, McMaster University, Hamilton, ON, Canada \\ 2 Psychology, Neuroscience and Behaviour, McMaster University, Hamilton, ON, Canada \\ ${ }^{3}$ Pairwise Affinity Inc., Dundas, ON, Canada
}

\section{Edited by:}

Robert W. Burgess, The Jackson

Laboratory, USA

Reviewed by:

Arianna Maffei, SUNY Stony Brook, USA

Da-Ting Lin, The Jackson

Laboratory, USA

*Correspondence:

Kathryn M. Murphy, McMaster Integrative Neuroscience Discovery and Study (MiNDS), McMaster

University, 1280 Main Street West, Hamilton, ON L8S 4K1, Canada. e-mail:kmurphy@mcmaster.ca
AMPA-receptor trafficking plays a central role in excitatory plasticity, especially during development. Changes in the number of AMPA receptors and time spent at the synaptic surface are important factors of plasticity that directly affect long-term potentiation (LTP), long-term depression (LTD), synaptic scaling, and the excitatory-inhibitory (E/I) balance in the developing cortex. Experience-dependent changes in synaptic strength in visual cortex (V1) use a molecularly distinct AMPA trafficking pathway that includes the GluA2 subunit. We studied developmental changes in AMPA receptor trafficking proteins by quantifying expression of GluA2, pGluA2 (GluA2serine880), GRIP1, and PICK1 in rat visual and frontal cortex. We used Western Blot analysis of synaptoneurosome preparations of rat visual and frontal cortex from animals ranging in age from P0 to P105. GluA2 and pGluA2 followed different developmental trajectories in visual and frontal cortex, with a brief period of over expression in frontal cortex. The over expression of GluA2 and pGluA2 in immature frontal cortex raises the possibility that there may be a period of GluA2-dependent vulnerability in frontal cortex that is not found in V1. In contrast, GRIP1 and PICK1 had the same developmental trajectories and were expressed very early in development of both cortical areas. This suggests that the AMPA-interacting proteins are available to begin trafficking receptors as soon as GluA2-containing receptors are expressed. Finally, we used all four proteins to analyze the surface-to-internalization balance and found that this balance was roughly equal across both cortical regions, and throughout development. Our finding of an exquisite surface-to-internalization balance highlights that these AMPA receptor trafficking proteins function as a tightly controlled system in the developing cortex.

Keywords: AMPA receptor, trafficking, critical period, GRIP, PICK1, visual cortex, frontal cortex, synaptic plasticity

\section{INTRODUCTION}

Functional maturation of the cortex is linked with dynamic changes in excitatory signaling via the glutamatergic system. Glutamate is the main excitatory neurotransmitter in the cortex and its action is mediated by three ionotropic receptors, $\mathrm{N}$-Methyl-D-aspartic acid (NMDA), kainate, and 2-amino3-(5-methyl-3-oxo-1,2-oxazol-4-yl) propanoic acid (AMPA) (Hollmann and Heinemann, 1994). Both NMDA and AMPA receptors are major players in the experience-dependent and dynamic changes that mark the critical period for synaptic plasticity in development (Collingridge and Singer, 1990; Malenka and Bear, 2004). Expression levels, subunit composition, and dynamic trafficking of these receptors effect development by influencing synaptic plasticity. In particular, a number of studies of visual cortical development have linked changes in AMPA receptor expression and cycling with long-term potentiation (LTP) (Malenka and Bear, 2004), long-term depression (LTD) (Heyen et al., 2003), synaptic scaling (Turrigiano and Nelson, 2004), and the excitatory-inhibitory (E/I) balance (Beston et al., 2010).

AMPA receptors are concentrated at synapses where they mediate the fast component $(2 \mathrm{~ms})$ of excitatory post-synaptic currents (EPSC) (Kleppe and Robinson, 1999). Typically, nascent glutamatergic synapses have NMDA receptors but lack AMPA receptors which are progressively recruited to the developing synapse (Petralia et al., 1999) by a rapid, activity-dependent process that increases the phosphorylation of surface AMPA receptors (Liao et al., 2001). Structurally, AMPA receptors are composed of four homologous subunits, GluA1-GluA4, that combine in varying stoichiometries to form ion channels with distinct functional properties (Hollmann and Heinemann, 1994; Dingledine et al., 1999). Most AMPA receptors contain the GluA2 subunit, which gives the receptor the characteristic qualities of calcium impermeability (Hollmann and Heinemann, 1994) and a linear current-voltage relationship (Hollmann and Heinemann, 1994; Dingledine et al., 1999). The expression of GluA2 increases with development in visual cortex (V1) (Herrmann, 1996) and is affected by monocular deprivation (Beston et al., 2010), that can lead to LTD in the deprived cortex (Heyen et al., 2003). Furthermore, blocking neural activity with tetrodotoxin (TTX) has been found to induce synaptic scaling in cultured visual cortical neurons leading to the insertion of GluA2 AMPA receptors at the synaptic surface (Gainey et al., 2009). 
AMPA receptors undergo multiple transcriptional and translational modifications that regulate and establish receptor function (Song and Huganir, 2002). The phosphorylation state of the receptor plays an important role in regulating synaptic plasticity (Raymond et al., 1993). For example, phosphorylation of GluA1 receptors at serine 845 is necessary for binocular deprivation to induce synaptic scaling in V1 (Goel et al., 2011). In addition, phosphorylation of GluA2 at serine 880 (pGluA2) is involved in LTD induction in the cerebellum (Chung et al., 2003) and hippocampus (Kim et al., 2001). Finally, brief monocular deprivation leads to phosphorylation of GluA2 receptors at serine 880 and subsequent induction of LTD in V1 (Heyen et al., 2003).

Results of electrophysiological studies of silent synapses in hippocampus first suggested that AMPA receptor levels are regulated (Isaac et al., 1995; Liao et al., 1995; Durand et al., 1996). Then AMPA receptor trafficking was directly characterized in cultured neurons treated with various pharmacological agents (Lissin et al., 1998; O'Brien et al., 1998). Enhancing or reducing synaptic function resulted in increases or decreases in AMPA receptor function, respectively, as measured by changes in mEPSC and receptor accumulation (Lissin et al., 1998; O'Brien et al., 1998). The trafficking processes of endocytosis, exocytosis, and recycling of AMPA receptors are highly regulated and require specific AMPA receptor-interacting proteins. GRIP1 and PICK1 are involved in trafficking GluA2-containing AMPA receptors in and out of the synapse (Chung et al., 2000), where GRIP1 is involved in stabilization of GluA2 containing receptors at the synaptic surface (Dong et al., 1997) and PICK1 stabilizes intracellular pools of the subunit (Gardner et al., 2005; Liu and Cull-Candy, 2005). To maintain homeostasis, AMPA receptor levels at the synaptic surface are dynamically regulated to compensate for variations in input (Turrigiano and Nelson, 2004). Interfering with GRIP1 function results in decreased GluA2 accumulation at the synaptic surface (Osten et al., 2000) and a loss of PICK1 function occludes synaptic scaling (Anggono et al., 2011). Together these results suggest that a balance between GRIP1 and PICK1 is an important part of the AMPA trafficking mechanism.

AMPA receptors cycle rapidly in and out of the synapse, and the relative levels of surface and internal pools of receptors contribute to controlling synaptic strength. Furthermore, synaptic scaling in the V1 depends on the trafficking of GluA2-containing AMPA receptors to the synaptic surface (Gainey et al., 2009) and depression of deprived-eye responses after monocular deprivation is dependent on internalization of those receptors (Yoon et al., 2009). Thus, experience-dependent changes in synaptic strength in V1 uses a molecularly distinct AMPA trafficking pathway.

In this study, we examined development of the synaptic proteins (GluA2, pGluA2, GRIP1, PICK1) involved that molecularly distinct AMPA trafficking pathway and compared the maturation of those proteins in visual and frontal cortex. Variations in the balance among the trafficking proteins will have profound effects on the dynamic nature of AMPA receptors and developmental plasticity that depends on AMPA receptors. Using Western blot analysis, we quantified the developmental trajectories in visual and frontal cortex and analyzed the balances among these synaptic proteins. We show a difference between visual and frontal cortex in the developmental trajectories for GluA2 and pGluA2, with a brief period of over expression in frontal cortex. In contrast, the AMPA interacting proteins GRIP1 and PICK1 followed similar development in visual and frontal cortex. Finally, we show that analysis of all four components uncovers a common surfaceto-internalization balance in visual and frontal cortex and that balance is maintained during development. This result implies that the trafficking system for GluA2-containing AMPA receptors is tightly controlled and develops as an integrated network across the cortex.

\section{MATERIALS AND METHODS ANIMALS AND TISSUE SAMPLES}

We studied changes in expression of a set of proteins involved in AMPA receptor trafficking in visual and frontal cortex of 28 Long-Evans rats (postnatal age 0-105 days). The animals were reared with normal visual experience in standard housing conditions and all experimental procedures were approved by the McMaster University Animal Research Ethics Board.

Cortical tissue samples were collected from V1 and frontal cortex guided by stereotaxic coordinates (Paxinos and Watson, 2007). Rats were euthanized with Euthanol (sodium pentobarbital, $0.165 \mathrm{mg} / \mathrm{g}$ ) and were transcardially perfused with cold 0.1 M Phosphate Buffered Saline (PBS, $4 \mathrm{C}$; pup: $1-2 \mathrm{ml} / \mathrm{min}$; adult: $4-5 \mathrm{ml} / \mathrm{min}$ ) until the circulating fluid was clear. The brain was removed from the skull and immersed in cold PBS. Small tissue samples (approximately $2 \times 2 \mathrm{~mm}$ ) of presumptive $\mathrm{V} 1$ and frontal cortex were taken, rapidly frozen on dry ice, and stored at $-80^{\circ} \mathrm{C}$.

\section{TISSUE SAMPLE PREPARATION}

The frozen tissue sample was suspended in cold tissue homogenization buffer ( $1 \mathrm{ml}$ buffer: $50 \mathrm{mg}$ tissue, $10 \mathrm{mM}$ HEPES, $2 \mathrm{mM}$ EDTA, $2 \mathrm{mM}$ EGTA, $0.5 \mathrm{mM}$ DTT, $10 \mathrm{mg} / \mathrm{L}$ leupeptin, $50 \mathrm{mg} / \mathrm{L}$ soybean trypsin inhibitor, $100 \mathrm{nM}$ microcystin, $0.1 \mathrm{mM}$ PMSF), and homogenized using a glass-glass Dounce homogenizer (Kontes, Vineland, NJ). A subcellular fractionation procedure (synaptoneurosomes) (Hollingsworth et al., 1985; Titulaer and Ghijsen, 1997; Quinlan et al., 1999) was used to obtain protein samples that were enriched for synaptic proteins. The homogenate was passed through a $5 \mu \mathrm{m}$ pore hydrophillic mesh filter (Millipore, Billerica, MA, USA) then centrifuged at $4^{\circ} \mathrm{C}$ and $1000 \times \mathrm{g}$ for $20 \mathrm{~min}$ to obtain the synaptic fraction of the membrane. The supernatant was removed, leaving a pellet enriched for synaptic proteins, the synaptoneurosome. The synaptic pellet was re-suspended in boiling 1\% sodium-dodecyl-sulfate (SDS) and stored at $-20^{\circ} \mathrm{C}$. Protein concentrations were determined using the bicinchonic acid (BCA) assay (Pierce, Rockford, IL, USA). Using antibodies for well-characterized synaptic markers, the synaptoneurosome samples were compared with whole homogenate to verify that there was a 2-3-fold enrichment for synaptic proteins. A control sample was made by combining a small amount of the prepared tissue sample from each of the cases. The samples prepared from P0. V1 had extremely low protein levels, too low to be used for immunoblotting. Therefore, 
for comparison purposes frontal cortex samples at P0 were excluded from analysis.

\section{IMMUNOBLOTTING}

A Western Blot analysis was performed using the synaptoneurosome samples to quantify protein expression. Samples (30 ug) were separated on $4-20 \%$ sodium-dodecyl-sulfate polyacrylamide (SDS-PAGE) gels (Pierce, Rockford, IL) in running buffer (100 mM Tris, 100 mM HEPES, 3 mM SDS; Pierce Biotechnology Inc, Rockford, IL) and were transferred to polyvinylidene difluoride (PVDF-FL) membranes (Millipore, Billerice, MA, USA). Each sample was run at least twice. The membranes were incubated in blocking buffer (Odyssey Blocking Buffer 1:1 with PBS) for $1 \mathrm{~h}$ (LI-COR Biosciences, Lincoln, NE), followed by incubation in primary antibody overnight at $4{ }^{\circ} \mathrm{C}$ using the following concentrations: GluA2, 1:2000 (Invitrogen, Camarillo, CA); pGluA2 (GluA2-ser880); 1:200 (PhosphoSolutions, Aurora, CO); GRIP1, 1:250 (BD Biosciences, San Diego, CA); PICK1, 1:200 (NeuroMab, Davis, CA); $\beta$-tubulin, 1:4000 (Invitrogen, Camarillo, CA). Blots were washed $(3 \times 10 \mathrm{~min})$ in PBS containing $0.05 \%$ Tween (PBS-T, Sigma, St. Louis, MO), incubated ( $1 \mathrm{~h}$, room temperature) in the appropriate IRDye labeled secondary antibody (Anti-Mouse, 1:8000, Anti-Rabbit, 1:10,000) (Li-cor Biosciences, Lincoln, NE), and washed in PBS-T $(3 \times 10 \mathrm{~min})$. Blots were scanned and fluorescence was quantified using the Odyssey Scanner infrared-imager (LI-COR Biosciences, Lincoln, NE, USA). Finally, the blots were stripped using a two-step blot restore kit (Blot Restore Membrane Rejuvenation kit, Millipore, Billerice, MA, USA) and further reprobed with additional antibodies.

\section{ANALYSIS}

Blots were scanned (Odyssey Infrared Scanner) and band fluorescence was quantified using densitometry (Li-cor Odyssey Software version 3.0; Li-cor Biosciences; Lincoln, NE, USA). To determine the density profile, the background was subtracted, the pixel intensity of the band was integrated, and then divided by the width of the band to control for variations in band size. $\beta$-tubulin was used as the loading control and we verified the absence of any age-related correlations in $\beta$-tubulin expression in both cortical areas ( $p$-values $>0.28$ ). A control sample (a mixture of all the samples) was run on each gel and the density of each sample was measured relative to the control sample (sample density/control density).

Scattergrams of protein expression by age were plotted and include the results from all the runs (light symbols) plus the average expression level for each sample (dark symbols). Curve fitting was done using the on-line curve-fitting tool zunzun.com and the goodness of fit was determined $\left(R^{2}\right)$. Smooth changes were fit with either a linear or exponential decay function, as appropriate. The time constant $(\tau)$ for the change in expression level was calculated for the exponential decay functions. Adult level of expression was defined as $3 \tau$ which is the age when expression reached $87.5 \%$ of the asymptotic level. To capture the peaked developmental over expression of GluA2 and pGluA2 in frontal cortex a membrane transport curve was fit to the results. We quantified the period of over expression in frontal cortex by identifying the age at the peak (maximum) of the curve and then the full width at half the maximum (FWHM) to determine the ages for the start and end of the period of over expression.

We examined the relationship between the two states of the AMPA receptor subunit (GluA2 and pGluA2) and the two AMPA receptor interacting proteins (GRIP1 and PICK1) by calculating the correlation for each pair. Next, we examined developmental changes for functional pairs of AMPA receptor trafficking proteins by calculating a series of indices that quantify the relative expression of AMPA receptor: subunit states, GluA2:pGluA2 = [(GluA2 - PGluA2)/(GluA2 + pGluA2)]; interacting proteins, GRIP1:PICK1 $=[($ GRIP1 - PICK1 $) /($ GRIP1 + PICK1 $)]$; surface components, GluA2:GRIP1 $=[($ GluA2 - GRIP1 $) /($ GluA2 + GRIP1)]; and internalization components, pGluA2:PICK1 = $[(\mathrm{pGluA} 2-\mathrm{PICK} 1) /(\mathrm{pGluA} 2+\mathrm{PICK} 1)]$. These contrast indices [e.g., $(\mathrm{A}-\mathrm{B}) /(\mathrm{A}+\mathrm{B})]$ are commonly used in signal processing and here provide a normalized difference between two proteins or two states of the GluA2 receptor. These indices allowed us to analyze relative changes between the GluA2 subunit states, interacting proteins, surface components, and internalization components that was independent of the developmental increases for each protein. Finally, we quantified the balance between surface-to-internalization proteins by calculating the difference between the surface and internalization indices: (GluA2:GRIP1) - (pGluA2:PICK1).

\section{RESULTS}

In this study, we characterized the expression of four components (GluA2, pGluA2, GRIP1, PICK1) involved in trafficking GluA2-containing AMPA receptors in and out of the synapse. Using Western Blot analysis, we quantified the developmental trajectories of the proteins and compared expression levels between the visual and frontal cortex to assess any differences in the developmental trajectories of sensory and non-sensory cortical areas.

\section{GluA2 AND pGIUA2 FOLLOW DIFFERENT DEVELOPMENTAL TRAJECTORIES IN VISUAL AND FRONTAL CORTEX}

We examined the development of the two states of the GluA2 subunit (non-phosphorylated-GluA2 and phosphorylated serine 880-pGluA2) in visual and frontal cortex to quantify the expression of AMPA receptors at the synaptic surface (GluA) versus internalized receptors (pGluA2).

We found that the development of GluA2 and pGluA2 was similar within a cortical area but followed different trajectories in visual and frontal cortex. Initially, expression of GluA2 and pGluA2 was very low in both visual and frontal cortex and then increased rapidly (Figure 1). In V1, there was steady increase that was well fit with a decay function. GluA2 increased fivefold $\left(R^{2}=0.74, p<0.0001\right)$ (Figure 1A) to reach adult levels

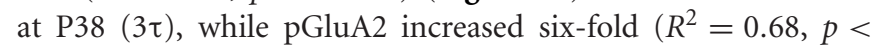

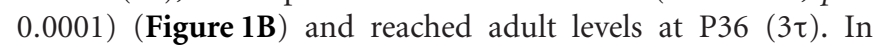
frontal cortex, both GluA2 (Figure 1C) and pGluA2 (Figure 1D) had a brief period of substantial over expression that peaked at P24 (membrane transport curve: GluA2 $-R^{2}=0.77, p<$ 0.0001 ; pGluA2 $\left.-R^{2}=0.79, p<0.0001\right)$. This period of over 

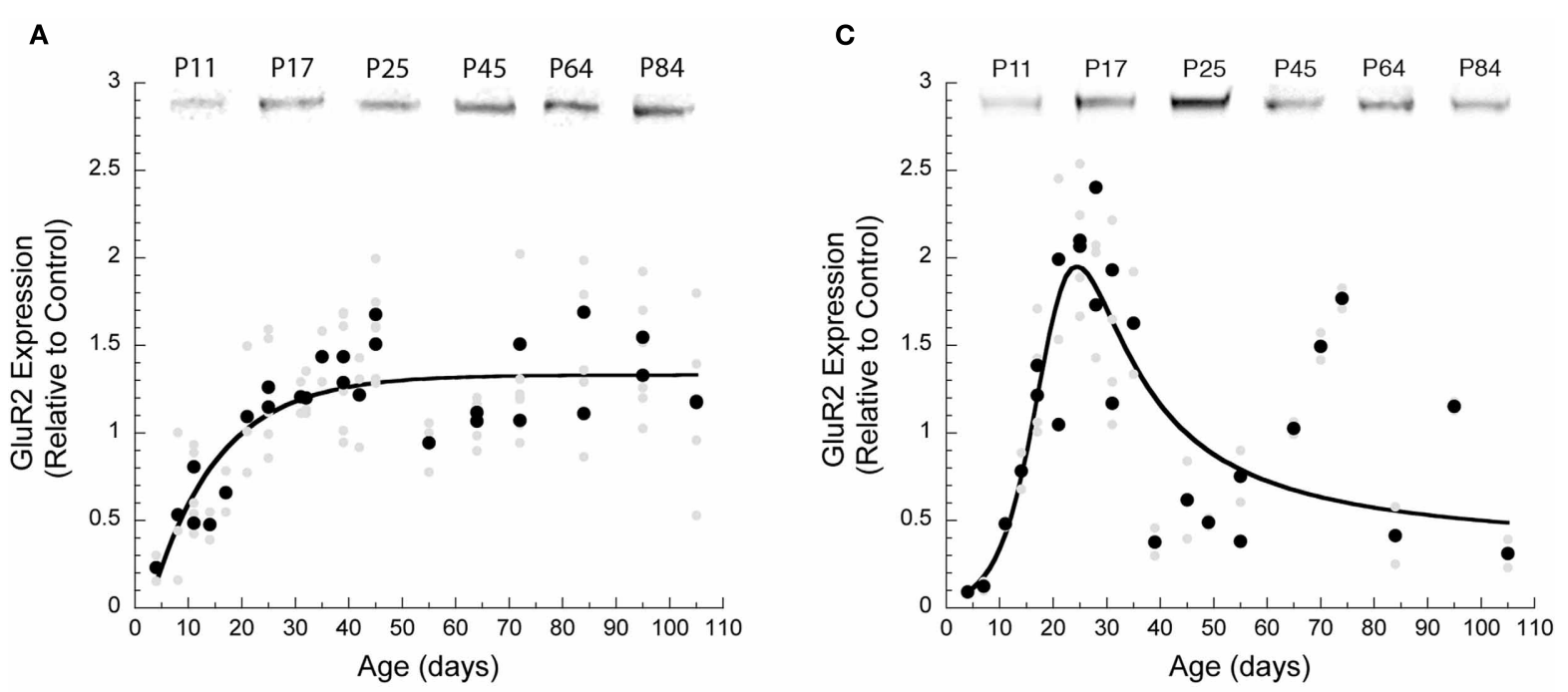

B

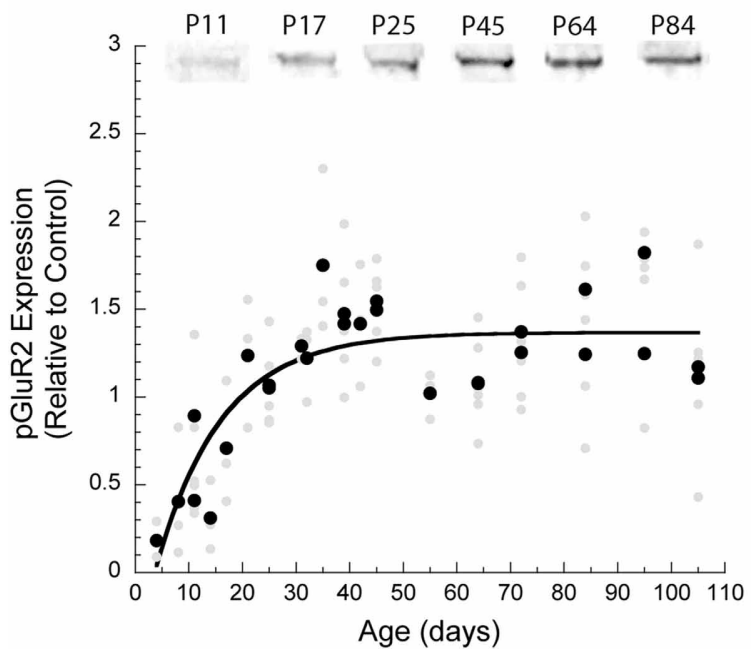

D

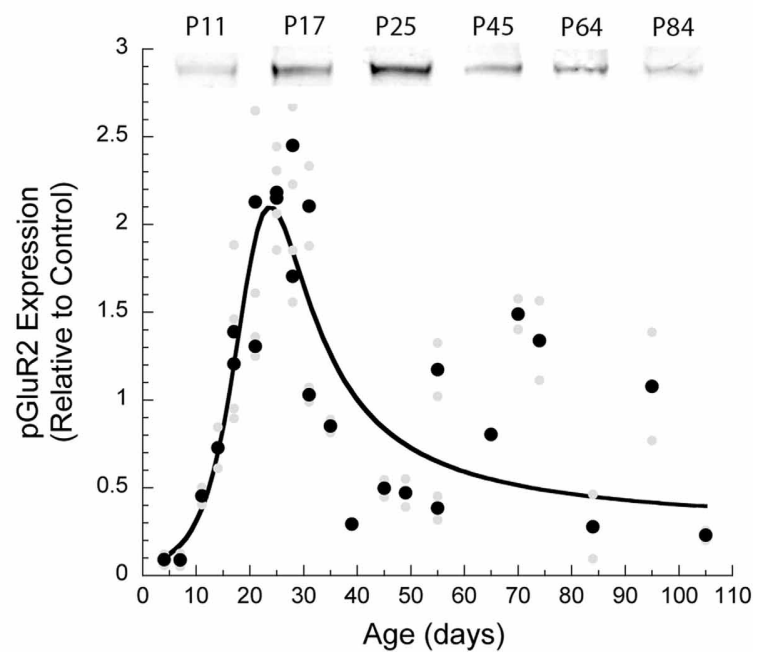

FIGURE 1 | Development of AMPA receptor subunits GluA2 and pGluA2 in visual and frontal cortex. There were significant differences in the developmental trajectories of GluA2 and pGluA2 in visual versus frontal cortex. All of the results were plotted for each run (light gray symbols) as well as the averages for each run (dark symbols). Exponential decay curves were fit to the data for visual cortex. (A) For GluA2 expression $\left(R^{2}=0.72\right.$,

expression in frontal cortex (FWHM) lasted from P18 to P35 for GluA2 and P19 to P32 for pGluA2.

\section{THE BALANCE BETWEEN GIUA2 AND pGIUA2 IS SIMILAR IN VISUAL AND FRONTAL CORTEX}

To assess the relationship between GluA2 and pGluA2 expression we calculated the correlation between these proteins and an index of the relative expression of the two states of the receptor subunit. In both cortical areas, the correlation between the expression of GluA2 and pGluA2 were very similar and close to a 1:1 relationship (Visual-Figure 2A: correlation, $r=0.88, p<0.0001$; Frontal-Figure 2C: correlation, $r=0.94, p<0.0001)$. To analyze how the balance between GluA2 and pGluA2 changed during development we calculated an index of the relative expression $p<0.0001)$ adult expression levels were reached at P38 $(3 \tau)$; (B) pGluA2 expression ( $R^{2}=0.68, p<0.0001$ ) reached adult levels by P36 $(3 \tau)$. The results for frontal cortex were fit with a membrane transport function. (C) In frontal cortex: GluA2 expression $\left(R^{2}=0.77, p<0.0001\right)$ had the maximum level at P24 (range P18-P35); (D) pGluA2 expression $\left(R^{2}=0.79\right.$, $p<0.0001$ ) had the maximum level at P24 (range P19 and P32). of these two states of the AMPA receptor subunit. The index was plotted by age and varies from -1 indicating only pGluA2, to 0 indicating equal pGluA2 and GluA2, to +1 indicating only GluA2. In V1, the index was initially slightly positive indicating more GluA2, but by P32 the two states were in balance $\left(3 \tau, R^{2}=0.37, p<0.0005\right)$ (Figure 2B). In frontal cortex, there was slightly more GluA2 except for a brief period between P18 and P30 when GluA2 and pGluA2 were approximately equal in expression (Figure 2D). Interestingly, the period when GluA2 and pGluA2 were balanced in frontal cortex coincided with the brief period of over expression. The similarities between the correlations and indices for GluA2 and pGluA2 in visual and frontal cortex suggest a common cortical balance for the two states of the AMPA receptor subunit throughout development. 

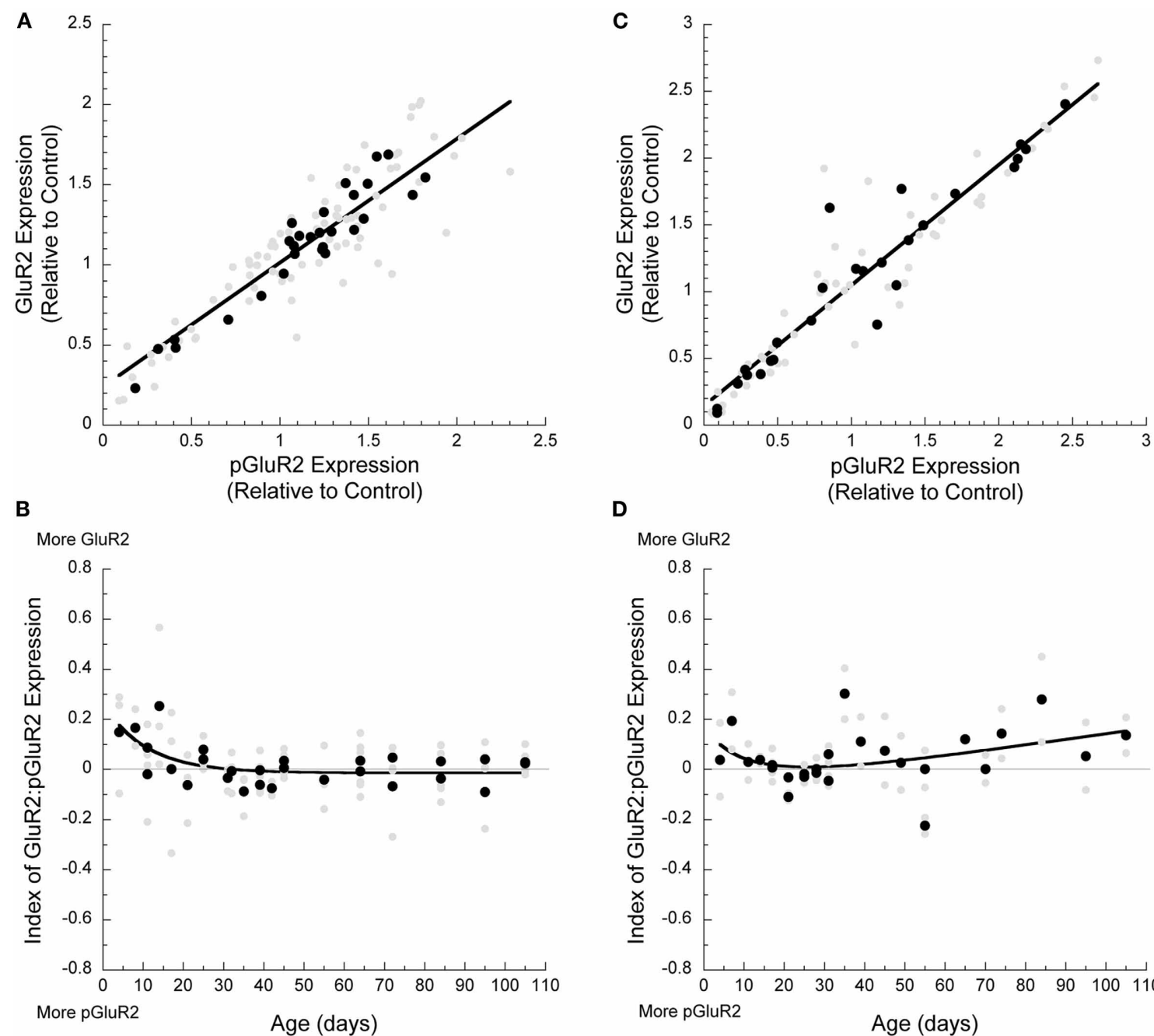

FIGURE 2 | Developmental changes in AMPA receptor subunit composition in visual and frontal cortex. (A) GluA2 and pGluA2 expression in both visual $(r=0.88, p<0.0001)$ and (C) frontal $(r=0.94, p<0.0001)$ cortex was highly correlated during development. The index of GluA2:pGluA2 expression during development showed that (B) in visual cortex, there was

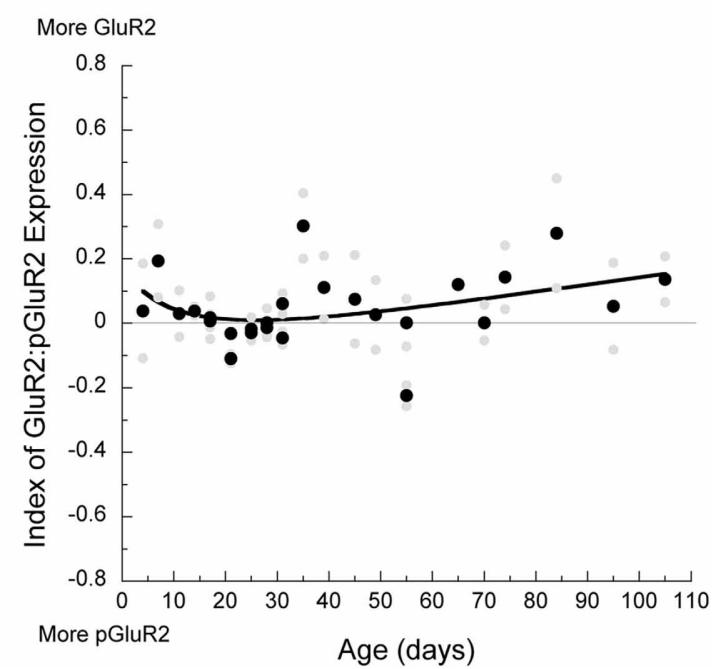

higher GluA2 expression initially, but a balance was reached by P33 $\left(3 \tau, R^{2}=0.37, p<0.0005\right)$. (D) In frontal cortex, the index remained in favor of relatively more GluA2 throughout development, except for a brief period of balance between P18 and P30 (membrane transport curve, $R^{2}=0.30, p=0.04$ )

\section{AMPA INTERACTING PROTEINS-GRIP1 AND PICK1-FOLLOW SIMILAR DEVELOPMENTAL TRAJECTORIES IN VISUAL AND FRONTAL CORTEX}

The AMPA interacting protein GRIP1 stabilizes the GluA2 subunit at the synaptic surface (Dong et al., 1997); however, when the GluA2 subunit is phosphorylated, it loses the interaction with GRIP1, is bound by PICK1, and becomes endocytosed (Seidenman et al., 2003). We examined the development of GRIP1 and PICK1 expression in visual and frontal cortex to quantify the maturation of these key AMPA receptor trafficking proteins.

During development the expression of GRIP1 and PICK1 increased by about $70 \%$ in V1 and 300\% in frontal cortex. The time courses of the developmental trajectories for GRIP1 and PICK1 were well described by a exponential decay function. In
V1, adult levels of GRIP1 were reached at P60 $\left(3 \tau, R^{2}=0.33, p=\right.$ 0.002 , Figure 3A) and PICK1 at P69 $\left(3 \tau, R^{2}=0.32, p=0.002\right.$, Figure 3B). In frontal cortex, GRIP1 reached adult levels at P56

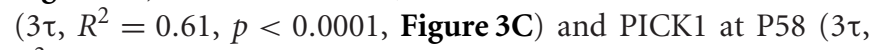
$R^{2}=0.63, p<0.0001$, Figure 3D). Although the magnitudes of the developmental changes for GRIP1 and PICK1 were greater in frontal cortex, the developmental time courses were similar to V1.

Next we assessed the relative level of expression between the surface (GRIP1) and internalizing (PICK1) AMPA interacting proteins. In $\mathrm{V} 1$, we found a strong relationship between the levels of GRIP1 and PICK1 expression $(r=0.72, p<$ 0.0001 , Figure 4A). Furthermore, that relationship was maintained throughout development with roughly equal expression of GRIP1 and PICK1 (Figure 4B). In frontal cortex, the correlation between GRIP1 and PICK1 expression was weaker, but still 

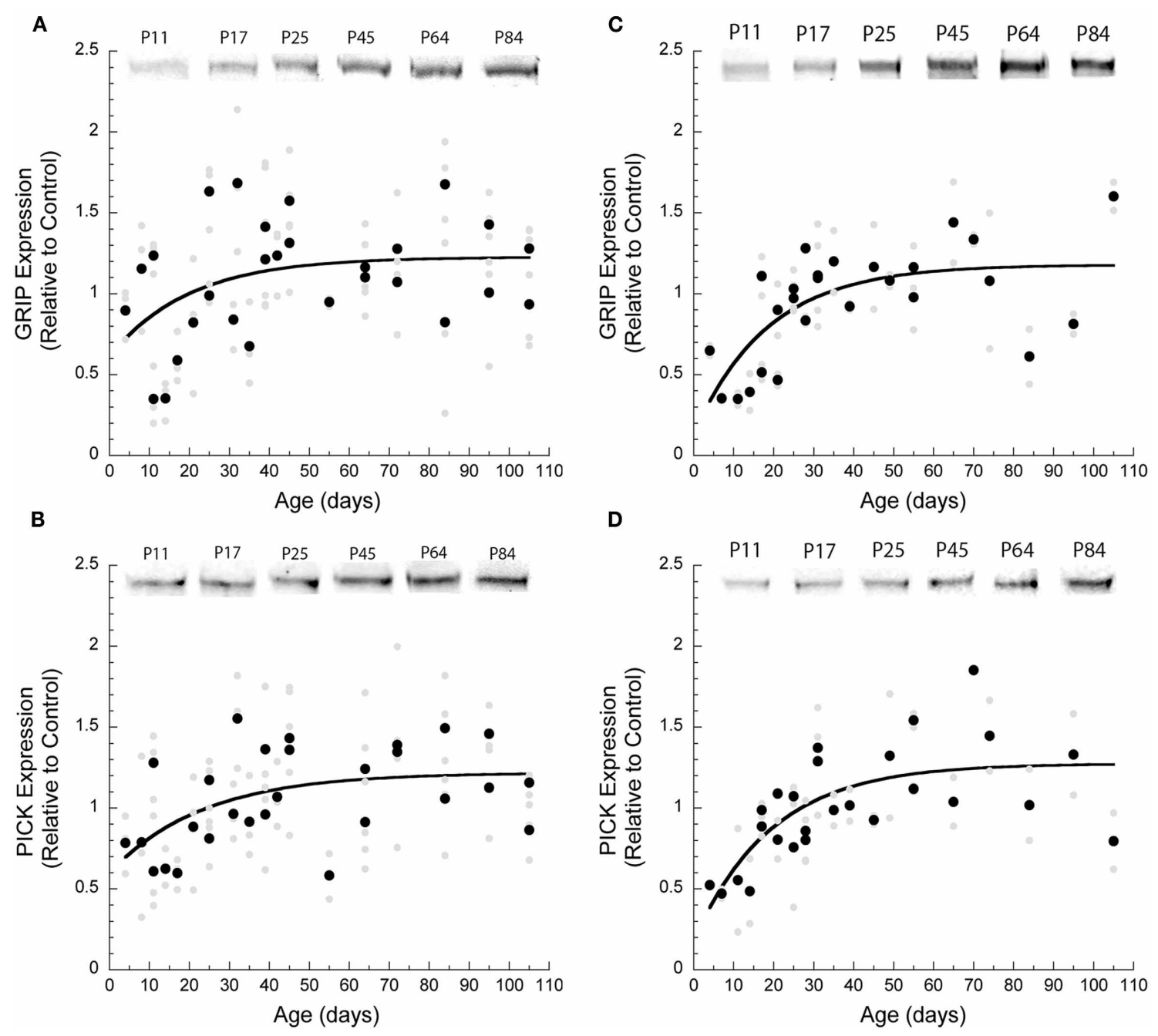

FIGURE 3 | Development of GRIP and PICK1 in visual and frontal cortex. The developmental trajectories for GRIP and PICK1 were similar in both cortical areas. Exponential decay curves were fit to all the data. (A) In visual cortex, GRIP expression levels increased by 1.7 times and reached adult

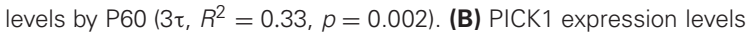

increased three-fold and reached adult values by P69 $\left(3 \tau, R^{2}=0.32\right.$, $p=0.002)$. (C) In frontal cortex, GRIP levels increased three-fold and reached adult levels by P56 ( $\left.3 \tau, R^{2}=0.61, p<0.0001\right)$. (D) Similarly, PICK1 expression increased three-fold during development and adult level was attained by P58 $\left(3 \tau, R^{2}=0.63, p<0.0001\right)$.

significant ( $r=0.48 ; p<0.0001$, Figure 4C), and expression of these two proteins was roughly balanced throughout development (Figure 4D).

\section{THE PAIRS OF SURFACE AND INTERNALIZATION PROTEINS DEVELOP SIMILARLY WITHIN A CORTICAL AREA BUT DIFFER BETWEEN VISUAL AND FRONTAL CORTEX}

We calculated two indices to examine development of the AMPA receptor subunits and interacting proteins associated with surface expressed (GluA2 and GRIP1) and internalized (pGluA2 and PICK1) receptors. We also analyzed how the surface and internalization indices changed throughout development for both visual and frontal cortex. We found that development of the two pairs of proteins was similar within each area but differed between cortical areas.
In V1, the surface (GluA2:GRIP1) and internalization (pGluA2:PICK1) indices followed similar trajectories (Figures 5A,B). Initially, there was relatively greater expression of the AMPA interacting proteins (more GRIP1 and PICK1) followed by an increase in the relative amounts of GluA2 and pGluA2 until the adult balances were reached at P13 for the surface index (GluA2:GRIP1, $3 \tau, R^{2}=0.62, p<0.0001$, Figure 5A) and slightly later at P22 for the internalization index (pGluA2:PICK1, $3 \tau, R^{2}=0.69, p<0.0001$, Figure 5B). In frontal cortex, the surface (Figure 5C) and internalization (Figure 5D) indices started in favor of the AMPA interacting proteins (more GRIP1 and PICK1), then rapidly shifted to more of the AMPA subunits (more GluA2 and pGluA2), followed by a shift back to relatively more expression of the interacting proteins. These developmental changes for the surface and 
A

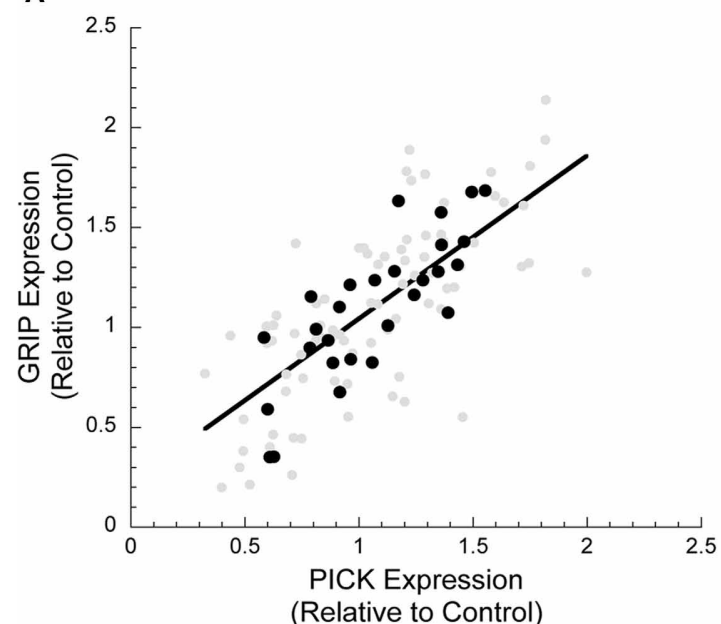

B

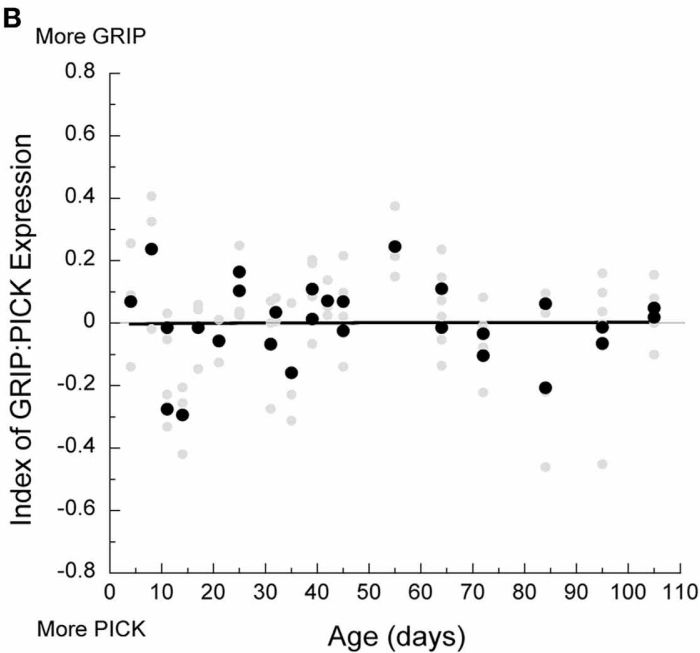

FIGURE 4 | Developmental changes in GRIP and PICK1 in visual and frontal cortex. (A) GRIP and PICK1 expression in visual cortex was highly correlated during development $(r=0.72, p<0.0001)$.

(B) The index of GRIP:PICK1 expression showed that the two proteins
C

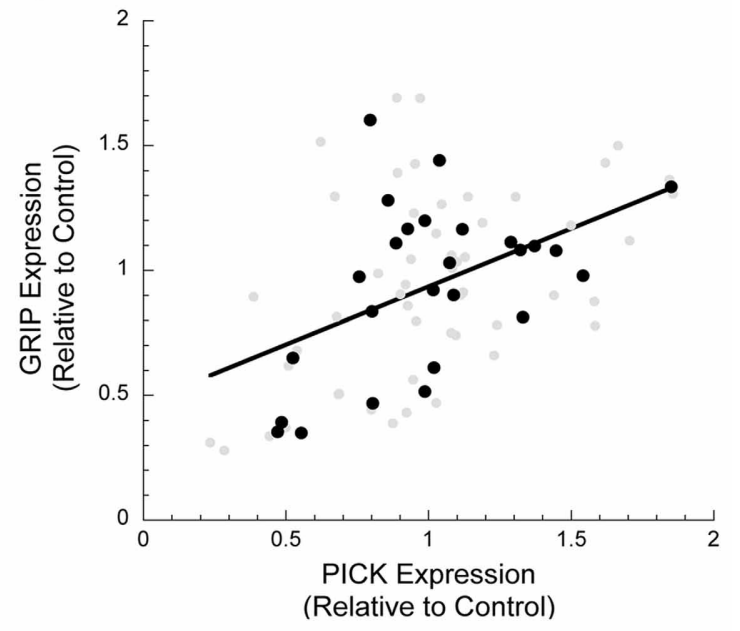

D

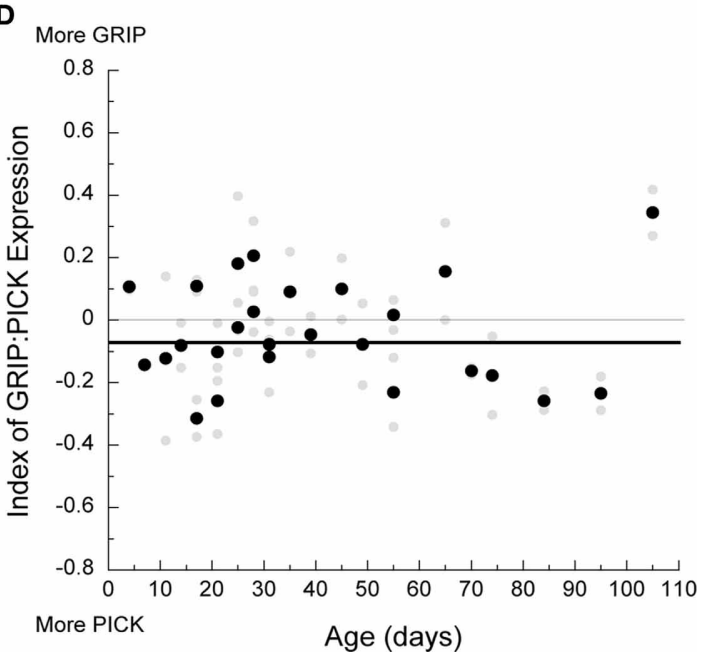

were balanced during postnatal development. (C) GRIP and PICK1 expression in frontal cortex was correlated during development $(r=0.48$, $p<0.0001$ ). (D) The index showed that GRIP and PICK1 develop in balance in frontal cortex. internalization indices in frontal cortex were well described by a membrane transport function (GluA2:GRIP1: $R^{2}=0.74$, $p<0.0001$; pGluA2:PICK1: $\left.R^{2}=0.77, p<0.0001\right)$ with peaks at P18 and P20 for the surface and internalization indices, respectively. The difference between cortical areas for the surface and internalization index was largely driven by the difference in GluA2 and pGluA2 expression. But the similarity within each cortical area raised the possibility that there may be a common overall balance between the surface and internalization proteins.

\section{THE AMPA RECEPTOR SURFACE-TO-INTERNALIZATION BALANCE IS CONSTANT DURING DEVELOPMENT AND THE SAME IN VISUAL AND FRONTAL CORTEX}

The balance between AMPA receptor proteins associated with surface expression (GluA2 and GRIP1) versus internalization
(pGluA2 and PICK1) will contribute to regulating the cycling of receptors in and out of the synapse. For example, more surface associated proteins suggests that more receptors may be held at the synapse and changes in the surface-to-internalization balance during development or differences between cortical areas may affect AMPA-dependent plasticity. As a first step to study these questions we examined the relationship between the surface and internalization proteins by assessing the correlation between the surface and internalization indices, and by calculating the difference between the two indices to quantify an AMPA surface-to-internalization balance.

In both visual $(r=0.61, p<0.0001)$ and frontal cortex $(r=$ $0.81, p<0.0001)$ there were strong correlations between the surface (GluA2:GRIP1) and internalization (pGluA2:PICK1) indices (Figure 6A). Moreover, the slopes for the relationships between 
A

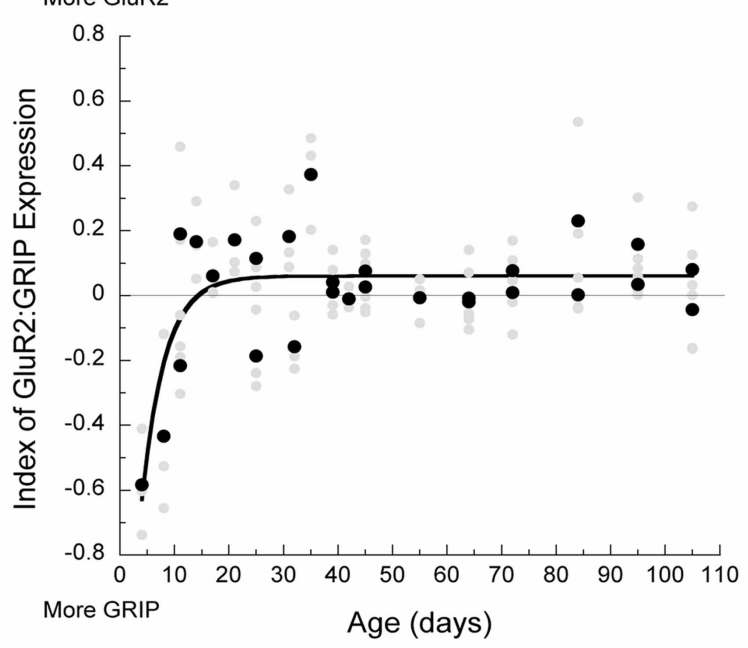

B

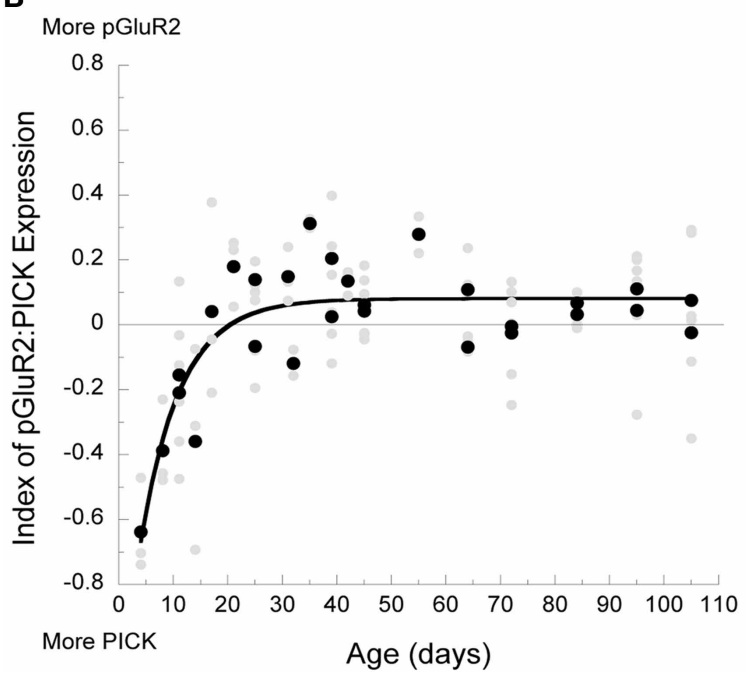

FIGURE 5 | Development of surface and internalized components in visual and frontal cortex. (A) Index of GluA2:GRIP during

development in visual cortex showed that initially more GRIP was present, but by $\mathrm{P} 13$, a balance with slightly more GluA2 was reached ( $\left.3 \tau, R^{2}=0.62, p<0.0001\right)$. (B) Index of pGluA2:PICK1 in visual cortex showed that more PICK1 was present early in development, but a balance was reached by P22 $\left(3 \tau, R^{2}=0.69, p<0.0001\right)$. (C) In frontal

\section{C}

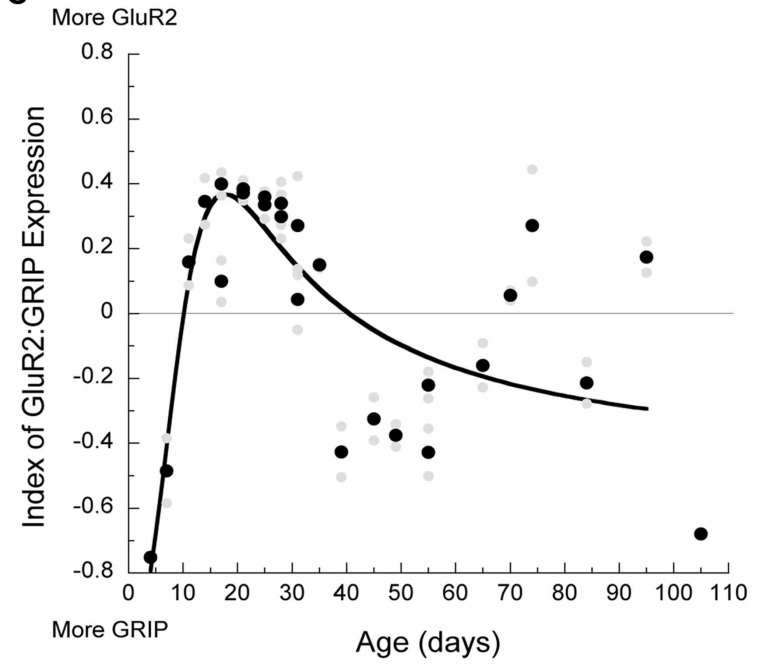

D

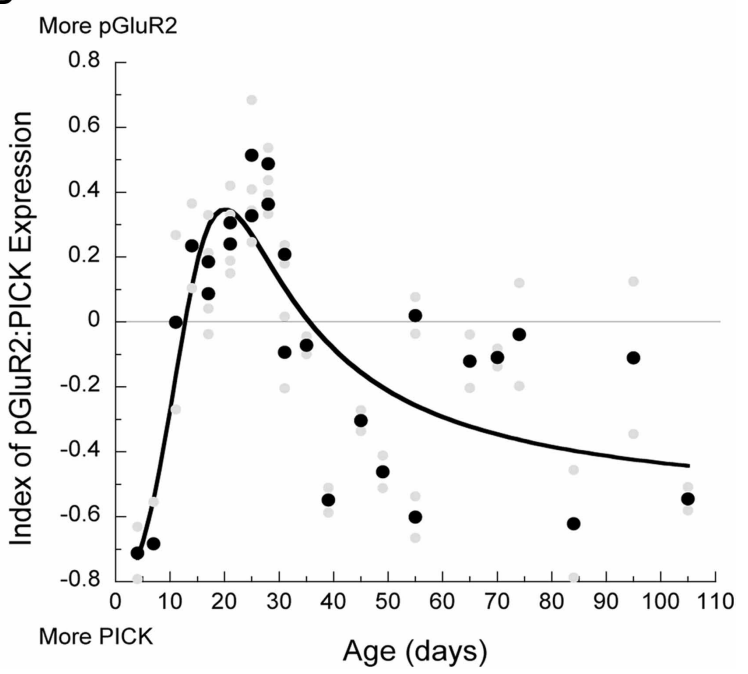

cortex, index of GluA2:GRIP was in favor of GRIP before P10, followed by an increase in GluA2 expression between P10 and P40, and then another shift to relatively more GRIP (membrane transport curve: $\left.R^{2}=0.74, p<0.0001\right)$. (D) Index of pGluA2:PICK1 was in favor of more PICK1 before P13, more pGluA2 between P13 and P34, and then another shift to relatively more PICK1 that persists throughout development.
GluA2:GRIP1 and pGluA2:PICK1 were similar in the two cortical areas, suggesting a common relationship between the surface and internalization mechanisms. To further examine this relationship we plotted the development of the surface-to-internalization balance for visual and frontal cortex (Figure 6B). We found that this surface-to-internalization balance was constant throughout development, and centered on 0 , indicating roughly equal expression of this set of surface and internalization proteins. Interestingly, the surface-to-internalization balance was the same in visual and frontal cortex. These observations suggest that AMPA receptor trafficking is tightly controlled and has a common balance in the developing cortex.

\section{DISCUSSION}

The results from this study support three main conclusions about the development of the AMPA trafficking proteins in rat cortex. First, the developmental trajectory for the two states of the GluA2 subunit differs between cortical areas. In frontal cortex, the development of GluA2 and pGluA2 had a brief period of exuberant expression and at P24 was almost four times greater than the adult levels (Figure 1). This result is similar to an earlier receptor autoradiography study that found an overshoot in binding to AMPA receptors (quisqualate) in the frontal cortex (Insel et al., 1990). In contrast, for V1 we found steady development of GluA2 and pGluA2 with no over expression. Our observation 


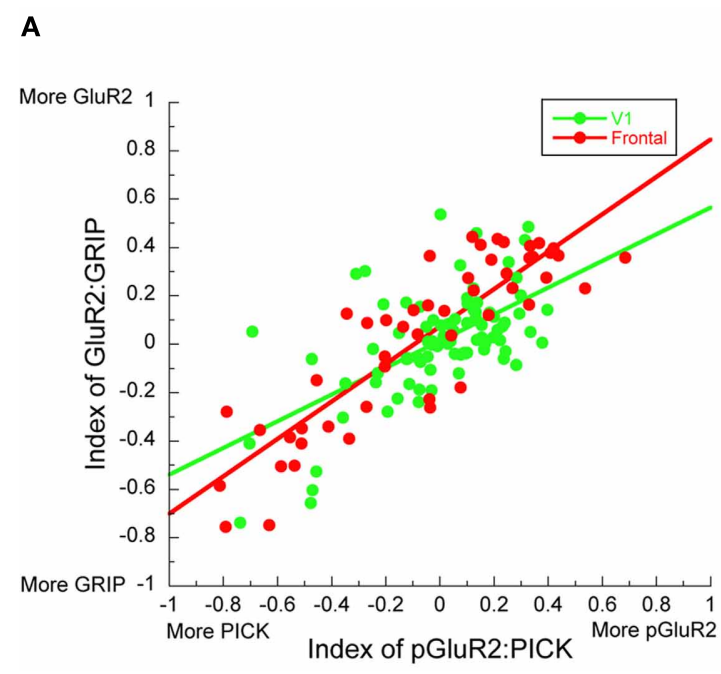

FIGURE 6 | Development of AMPA receptor in visual and frontal cortex. (A) There was a strong correlation between the indices for GluA2:GRIP and pGluA2:PICK1 in both visual (green symbols) $(r=0.61, p<0.0001)$ and

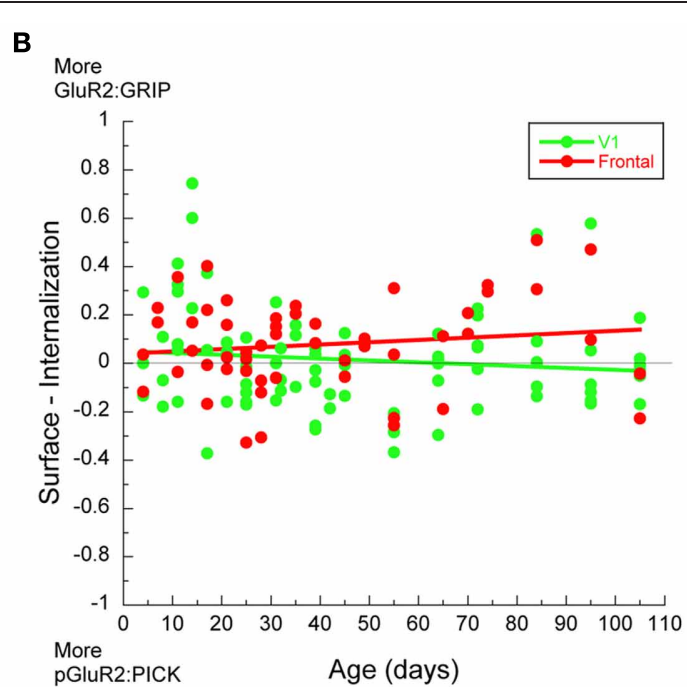

frontal cortex (red symbols) $(r=0.81, p<0.0001)$. (B) The difference between the indices for GluA2:GRIP and pGluA2:PICK1 as a function of age showed a tight surface-to-internalization balance throughout development. of steady GluA2 development in rat V1 challenges the conventional view of AMPA over expression during cortical development found using receptor binding (Insel et al., 1990) or in other species (ferret-Herrmann, 1996; cat-Beston et al., 2010). The difference may be species specific or because we used a synaptoneurosome assay which provides more specific information about receptors located at the synapse than all receptors as are labeled by receptor binding. Since the number of AMPA receptors sets the strength of excitatory transmission and influences synaptic plasticity, the developmental difference in GluA2 expression between visual and frontal cortex suggests that the refinement of cortical circuits differs between regions. Furthermore, the overshoot of GluA2 in frontal cortex implies a period of rapid synaptic change that may be particularly vulnerable to AMPAdependent plasticity and associated with the time when injury to the frontal cortex has its most deleterious effect (Halliwell et al., 2009).

Second, development of the AMPA interacting proteins associated with surface (GRIP1) and internalized (PICK1) receptors is similar in visual and frontal cortex. There was early expression of GRIP1 and PICK1 in both regions, followed by gradual developmental increases. Initially, the expression of GRIP1 and PICK1 was greater than the matching GluA2 or pGluA2 expression (this is logically necessary based on the previous sentence, so it's a bit redundant). GRIP1 is necessary for the accumulation of GluA2 at the synapse (Osten et al., 2000), and PICK1 reduces surface expression of GluA2 (Perez et al., 2001) by retaining receptors inside the synapse (Citr et al., 2010). Thus, our data showing early expression of GRIP1 and PICK1 supports a model where the synaptic accumulation and internalization of GluA2-containing receptors is regulated as soon as the receptors are expressed. Furthermore, the exquisite balance between GRIP1 and PICK1 expression throughout development suggests fine regulation of the interacting proteins that are part of AMPA receptor trafficking. The early expression and fine regulation could underlie the rapid insertion of AMPA receptors that converts silent synapses into functional ones (Rumpel et al., 1998).

Third, throughout cortical development there is a tight balance among the four AMPA trafficking components with roughly equal expression of the surface and internalization components. We calculated the surface-to-internalization balance to quantify changes in the relative expression of surface (GluA2:GRIP1) and internalization (pGluA2:PICK1) proteins that regulate the highly dynamic trafficking of AMPA receptors to and from cortical synapses (Shepherd and Huganir, 2007). The consistent surface-to-internalization balance points to exquisite control over the cycling of AMPA receptors in and out of cortical synapses. Moreover, even though we found differences in the development of GluA2 expression between visual and frontal cortex, the surface-to-internalization balance was the same in the two regions. Taken together, the common surface-to-internalization balance suggests that developmental excitatory plasticity is more sensitive to changes in the number of receptors, than to changes in the rate of AMPA receptor trafficking.

A number of recent studies have shown the tremendous complexity of the pathways involved in trafficking AMPA receptors to and from the synapse (for review see Anggono and Huganir, 2012). We have quantified the developmental changes in expression for just four of the components in those pathways and a complete understanding will need to include quantification of the full complement of interacting proteins. In addition, it is clear that there is cross-talk between the signaling pathways and proteinprotein regulation of interacting proteins that affects their roles in AMPA trafficking and may even shift their function from participation in surface to internalization of AMPA receptors. For example, GRIP1 can participate in AMPA receptor endocytosis (Osten et al., 2000), exocytosis (Mao et al., 2010), and holding receptors intracellularly (Braithwaite et al., 2002). This functional diversity 
for individual interacting proteins adds to the complexity and dynamic nature of AMPA receptor trafficking. The indices that we used in this study quantify the balances among the proteins and provide initial insights into functional changes during development. Looking at the balances and ratios among synaptic proteins is often used as a first step in the process of understanding the interactions that drive function, especially during development. For example, the initial prevalence of GluN2B prevents GluA2 expression (Hall et al., 2007), and the developmental shift in the GluN2A:GluN2B balance changes the function of GluN receptors and affects ocular dominance plasticity in V1 (Cho et al., 2009). The surface and internalization indices that we used provide one view of what is a very complex system, and more sophisticated multidimensional analyses and modeling will be needed to gain a full appreciation for how the AMPA receptor trafficking system functions.

AMPA receptor trafficking plays a central role in excitatory plasticity (Malinow and Malenka, 2002), especially during development (Kerchner and Nicoll, 2008). A number of studies have shown that experience-dependent plasticity in the V1 involves changes in AMPA receptor expression. These include monocular deprivation induced loss of GluA2 (Beston et al., 2010) or increase in pGluA2 (Heyen et al., 2003), and selective involvement of AMPA receptor expression in perceptual learning (Frenkel et al., 2006). Furthermore, bidirectional changes in GluA2 expression in V1 (Smith et al., 2009) underlie synaptic physiology plasticity that leads to experience-dependent LTP (Malenka and Bear, 2004), or LTD (Heyen et al., 2003; Yoon et al., 2009). Synaptic scaling in V1 (Turrigiano and Nelson, 2004) is also AMPA-dependent and uses a GluA2-specific trafficking pathway to either increase surface expression (Gainey et al., 2009) or internalize GluA2containing receptors (Yoon et al., 2009). In frontal cortex, there have been fewer studies of AMPA-dependent developmental plasticity. A recent study, however, has shown that prenatal exposure to cocaine markedly reduces GluA2 and GluA3 expression measured at P21 in rat frontal cortex (Bakshi et al., 2009). That age corresponds with the peak of GluA2 expression that we found for normal animals and perhaps changes in GluA2-dependent LTP, LTD, and synaptic scaling underlie the long-term effects on brain development, anxiety, and cognitive function caused by prenatal cocaine exposure.

The highly dynamic process of trafficking AMPA receptors involves several proteins to endo- and exo-cytose receptors (Shepherd and Huganir, 2007). We studied development of the GluA2-interacting proteins GRIP1 and PICK1 because they play a critical role in GluA2-specific LTD and synaptic scaling. PICK1 participates in the regulated endocytosis of GluA2-containing receptors and can interact with intracellular signaling pathways that modify AMPA receptor trafficking (Hanley, 2008; Citr et al., 2010). The surface level of GluA2-containing AMPA receptors is reduced when PICK1 binds to the C-terminus of the subunit (Perez et al., 2001) and this PICK1-dependent internalization regulates LTD (Kim et al., 2001) by holding the receptor inside the synapse (Citr et al., 2010). This key role for PICK1 in regulating LTD is a strong indicator that PICK1 contributes to LTD in V1 ocular dominance plasticity (Yoon et al., 2009). In the hippocampus, however, loss of PICK1 impairs LTP and LTD synaptic plasticity in adult but not juvenile mice (Volk et al., 2010), so future studies are needed to determine the role of PICK1 in developmental ocular dominance plasticity. Finally, a recent study has uncovered a specific role for PICK1 in inactivity-induced synaptic scaling of cortical neuronal excitability (Anggono et al., 2011). They showed a loss of PICK1 expression following chronic activity blockade of cortical neurons and abnormal trafficking of GluA2-containing receptors when PICK1 function was knocked out. Thus, PICK1 function is an essential component of inactivity-induced synaptic scaling plasticity that increases synaptic strength. Our finding that PICK1 is expressed early in the developing cortex indicates that right from the youngest postnatal ages neuronal excitability can be increased to adjust for low levels of activity.

The other GluA2-interacting protein that we studiedGRIP1-plays essential roles in surface expression of GluA2containing AMPA receptors (Shepherd and Huganir, 2007). GRIP1 has been implicated in regulating the rate of endocytosis (Osten et al., 2000) and in facilitating the reinsertion of internalized AMPA receptors back into the synapse (Mao et al., 2010). The early expression of GRIP1 in the developing visual and frontal cortex indicates that surface expression and trafficking is regulated as soon as GluA2-containing receptors are expressed. The role, however, of GRIP1 in functional development of V1 has not been studied. In frontal cortex, regulation of AMPA trafficking is disrupted by prenatal exposure to cocaine that causes hyperphosphorylation of GRIP1 and reduces postnatal expression of synaptic GluA2 (Bakshi et al., 2009). Those findings led Bakshi et al. to propose suppressing the excessive GRIP1 phosphorylation as a therapeutic to treat the consequences of prenatal cocaine exposure. In addition, a recent study has linked changes in the function of GRIP1 with autism in humans (Mejias et al., 2011). Sequencing of GRIP1 in individuals with autism uncovered five rare missense variants in the genomic sequence near the encoding of PDZ4-6. In an animal model, the mutation altered the interaction between GRIP1 and GluA2-containing receptors and led to abnormal social behavior. Importantly, more severe genotypes were linked with greater cognitive impairment suggesting that GRIP1 mutations modify the severity of the behaviors that characterize autism.

It is clear that the set of AMPA trafficking proteins that we studied-GRIP1, PICK1, GluA2, and pGluA2-play essential roles in normal and abnormal development of cortical function. There is still, however, much to learn about the precise roles for these proteins in synaptic plasticity and development of cortical circuits. It has been challenging to elucidate the functions of the interacting proteins and link them with regulation of GluA2dependent developmental plasticity because of the many proteins that contribute to AMPA receptor trafficking (Duprat et al., 2003; Shepherd and Huganir, 2007; Anggono and Huganir, 2012). Our finding of an exquisite surface-to-internalization balance highlights that these proteins function as a tightly controlled system and the need to study the system as a whole to understand how trafficking of AMPA receptors affects cortical development and function. 


\section{REFERENCES}

Anggono, V., Clem, R. L., and Huganir, R. L. (2011). PICK1 loss of function occludes homeostatic synaptic scaling. J. Neurosci. 31, 2188-2196.

Anggono, V., and Huganir, R. L. (2012). Regulation of AMPA receptor trafficking and synaptic plasticity. Curr. Opin. Neurobiol. doi: 10.1016/j.conb.2011.12.006. [Epub ahead of print].

Bakshi, K., Gennaro, S., Chan, C. Y., Kosciuk, M., Liu, J., Stucky, A., Trenkner, E., Friedman, E., Nagele, R. G., and Wang, H. Y. (2009). Prenatal cocaine reduces AMPA receptor synaptic expression through hyperphosphorylation of the synaptic anchoring protein GRIP. J. Neurosci. 29, 6308-6319.

Beston, B. R., Jones, D. G., and Murphy, K. M. (2010). Experiencedependent changes in excitatory and inhibitory receptor subunit expression in visual cortex. Front. Neurosci. 2:138. doi: 10.3389/fnsyn. 2010.00138

Braithwaite, S. P., Xia, H., and Malenka, R. C. (2002). Differential roles for NSF and GRIP/ABP in AMPA receptor cycling. Proc. Natl. Acad. Sci. U.S.A. 99, 7096-7101.

Cho, K. A., Khibnik, L., Philpot, B. D., and Bear, M. F. (2009). The ratio of NR2A/B NMDA receptor subunits determines the qualities of ocular dominance plasticity in visual cortex. Proc. Natl. Acad. Sci. U.S.A. 106, 5377-5382.

Chung, H. J., Steinberg, J. P., Huganir, R. L., and Linden, D. J. (2003). Requirement of AMPA receptor GluR2 phosphorylation for cerebellar long-term depression. Science 300, 751-755.

Chung, H. J., Xia, J., Scannevin, R. H., Zhang, X., and Huganir, R. L. (2000). Phosphorylation of the AMPA receptor subunit GluR2 differentially regulates its interaction with PDZ domain-containing proteins. J. Neurosci. 20, 7258-7267.

Citr, A., Bhattacharyya, S., Ma, C., Morishita, W., Fang, S., Rizo, J., and Rc, R. C. M. (2010). Calcium binding to PICK1 is essential for the intracellular retention of AMPA receptors underlying long-term depression. J. Neurosci. 30, 16437-16452.

Collingridge, G. L., and Singer, W. (1990). Excitatory amino acid receptors and synaptic plasticity. Trends Pharmacol. Sci. 11, 290-296.

Dingledine, R., Borges, K., Bowie, D., and Traynelis, S. F. (1999). The glutamate receptor ion channels. Pharmacol. Rev. 51, 7-61.

Dong, H., O’Brien, R. J., Fung, E. T., Lanahan, A. A., Worley, P. F., and Huganir, R. L. (1997). GRIP: a synaptic $\mathrm{PDZ}$ domain-containing protein that interacts with AMPA receptors. Nature 286, 279-284.

Duprat, F., Daw, M., Lim, W., Collingridge, G., and Isaac, J. (2003). GluR2 protein-protein interactions and the regulation of AMPA receptors during synaptic plasticity. Philos. Trans. R. Soc. Lond. B Biol. Sci. 358, 715-720.

Durand, G. M., Kovalchuk, Y., and Konnerth, A. (1996). Long-term potentiation and functional synapse induction in developing hippocampus. Nature 381, 71-75.

Frenkel, M. Y., Sawtell, N. B., Diogo, A. C., Yoon, B., Neve, R. L., and Bear, M. F. (2006). Instructive effect of visual experience in mouse visual cortex. Neuron 51, 339-349.

Gainey, M. A., Hurvitz-Wolff, J. R., Lambo, M. E., and Turrigiano, G. G. (2009). Synaptic scaling requires the GluR2 subunit of the AMPA receptor. J. Neurosci. 29, 6479-6489.

Gardner, S. M., Takamiya, K., Xia, J., Suh, J. G., Johnson, R., Yu, S., and Huganir, R. L. (2005). Calciumpermeable AMPA receptor plasticity is mediated by subunit-specific interactions with PICK1 and NSF. Neuron 45, 903-915.

Goel, A., Xu, L. W., Snyder, K. P., Song, L., Goenaga-Vazquez, Y., Megill, A., Takamiya, K., Huganir, R. L., and Lee, H. K. (2011). Phosphorylation of AMPA receptors is required for sensory deprivation-induced homeostatic synaptic plasticity. PLoS ONE 6:e18264. doi:10.1371/journal.pone.0018264

Hall, B. J., Ripley, B., and Ghosh, A. (2007). NR2B Signaling regulates the development of synaptic AMPA receptor current. J. Neurosci. 27, 13446-13456.

Halliwell, C., Comeau, W., Gibb, R., Frost, D. O., and Kolb, B. (2009). Factors influencing frontal cortex development and recovery from early frontal injury. Dev. Neurorehabil. 12, 269-278.

Hanley, J. G. (2008). PICK1: a multitalented modulator of AMPA receptor trafficking. Pharmacol. Ther. 2, 276-282.

Herrmann, K. (1996). Differential distribution of AMPA receptors and glutamate during pre- and postnatal development in the visual cortex of ferrets. J. Comp. Neurol. 4, 1-17.

Heyen, A. J., Yoon, B. J., Liu, C. H., Chung, H. J., Huganir, R. L., and Bear, M. F. (2003). Molecular mechanism for loss of visual cortical responsiveness following brief monocular deprivation. Nat. Neurosci. 6, 854-862.
Hollingsworth, E. B., Mcneal, E. T., Burton, J. L., Williams, R. J., Daly, J. W., and Creveling, C. R. (1985). Biochemical characterization of a filtered synaptoneurosome preparation from guinea pig cerebral cortex: cyclic adenosine 3':5'-monophosphate-generating systems, receptors, and enzymes. $J$. Neurosci. 5, 2240-2253.

Hollmann, M., and Heinemann, S. (1994). Cloned glutamate receptors. Annu. Rev. Neurosci. 17, 31-108.

Insel, T. R., Miller, L. P., and Gelhard, R. E. (1990). The ontogeny of excitatory amino acid receptors in rat forebrain-I. N-methyl-Daspartate and quisqualate receptors. Neuroscience 35, 31-43.

Isaac, J. T., Nicoll, R. A., and Malenka, R. C. (1995). Evidence for silent synapses: implications for the expression of LTP. Neuron 15 427-434.

Kerchner, G. A., and Nicoll, R. A. (2008). Silent synapses and the emergence of a postsynaptic mechanism for LTP. Nat. Rev. Neurosci. 9 , 813-825.

Kim, C. H., Chung, H. J., Lee, H K., and Huganir, R. L. (2001). Interaction of the AMPA receptor subunit GluR2/3 with PDZ domains regulates hippocampal long-term depression. Proc. Natl. Acad. Sci. U.S.A. 98, 11725-11730.

Kleppe, I. C., and Robinson, H. P. (1999). Determining the activation time course of synaptic AMPA receptors from openings of colocalized NMDA receptors. Biophys. J. $77,1418-1427$.

Liao, D., Hessler, N. A., and Malinow, R. (1995). Activation of postsynaptically silent synapses during pairing-induced LTP in CA1 region of hippocampal slice. Nature 375, 400-404.

Liao, D., Scannevin, R. H., and Huganir, R. L. (2001). Activation of silent synapses by rapid activitydependent synaptic recruitment of AMPA receptors. J. Neurosci. 21, 6008-6017.

Lissin, D. V., Gomperts, S. N., Carroll, R. C., Christine, C. W., Kalman, D. Kitamura, M., Hardy, S., Nicoll, R. A., Malenka, R. C., and Zastrow, M. V. (1998). Activity differentially regulates the surface expression of synaptic AMPA and NMDA glutamate receptors. Proc. Natl. Acad. Sci. U.S.A. 95, 7097-7102

Liu, S. J., and Cull-Candy, S. G. (2005). Subunit interaction with PICK and GRIP controls Ca2+ permeability of AMPARs at cerebellar synapses. Nat. Neurosci. 8 , 768-775.
Malenka, R. C., and Bear, M. F. (2004). LTP and LTD: an embarrassment of riches. Neuron 44, 5-21.

Malinow, R., and Malenka, R. C. (2002). AMPA receptor trafficking and synaptic plasticity. Annu. Rev. Neurosci. 25, 103-126.

Mao, L., Takamiya, K., Thomas, G., Lin, D. T., and Huganir, R. L. (2010). GRIP1 and 2 regulate activitydependent AMPA receptor recycling via exocyst complex interactions. Proc. Natl. Acad. Sci. U.S.A. 107, 19038-19043.

Mejias, R., Adamczyk, A., Anggono, V., Niranjan, T., Thomas, G. M., Sharma, K., Skinner, C., Schwartz, C. E., Stevenson, R. E., Fallin, M. D., Kaufmann, W., Pletnikov, M., Valle, D., Huganir, R. L., and Wang, T. (2011). Gain-of-function glutamate receptor interacting protein 1 variants alter GluA2 recycling and surface distribution in patients with autism. Proc. Natl. Acad. Sci. U.S.A. 108, 4920-4925.

O’Brien, R. J., Kamboj, S., Ehlers, M. D., Rosen, K. R., Fischbach, G. D., and Huganir, R. L. (1998). Activitydependent modulation of synaptic AMPA receptor accumulation. Neuron 21, 1067-1078.

Osten, P., Khatri, L., Perez, J. L., Köhr, G., Giese, G., Daly, C., Schulz, T. W., Wensky, A., Lee, L. M., and Ziff, E. B. (2000). Mutagenesis reveals a role for $\mathrm{ABP} / \mathrm{GRIP}$ binding to GluR2 in synaptic surface accumulation of the AMPA receptor. Neuron 27, 313-325.

Paxinos, G., and Watson, C. (2007). The Rat Brain in Stereotaxic Coordinates. Amsterdam: Elsevier Academic.

Perez, J. L., Khatri, L., Chang, C., Srivastava, S., Osten, P., and Ziff, E. B. (2001). PICK1 targets activated protein kinase Calpha to AMPA receptor clusters in spines of hippocampal neurons and reduces surface levels of the AMPA-type glutamate receptor subunit 2. J. Neurosci. 21, 5417-5428.

Petralia, R. S., Esteban, J. A., Wang, Y. X., Partridge, J. G., Zhao, H. M., Wenthold, R. J., and Malinow, R. (1999). Selective acquisition of AMPA receptors over postnatal development suggests a molecular basis for silent synapses. Nat Neurosci. 2, 31-36.

Quinlan, E. M., Olstein, D. H., and Bear, M. F. (1999). Bidirectional, experience-dependent regulation of N-methyl-D-aspartate receptor subunit composition in the rat visual cortex during postnatal development. Proc. Natl. Acad. Sci. U.S.A. 96, 12876-12880. 
Raymond, L. A., Blackstone, C. D., and Huganir, R. L. (1993). Phosphorylation of amino acid neurotransmitter receptors in synaptic plasticity. Trends Neurosci. 16, 147-153.

Rumpel, S., Hatt, H., and Gottmann, K. (1998). Silent synapses in the developing rat visual cortex: evidence for postsynaptic expression of synaptic plasticity. J. Neurosci. 18, 8863-8874.

Seidenman, K. J., Steinberg, J. P., Huganir, R., and Malinow, R. (2003). Glutamate receptor subunit 2 Serine 880 phosphorylation modulates synaptic transmission and mediates plasticity in CA1 pyramidal cells. J. Neurosci. 23, 9220-9228.

Shepherd, J. D., and Huganir, R. L. (2007). The cell biology of synaptic plasticity: AMPA receptor trafficking. Annu. Rev. Cell Dev. Biol. 23, 613-643.

Smith, G. B., Heynen, A. J., and Bear, M. F. (2009). Bidirectional synaptic mechanisms of ocular dominance plasticity in visual cortex. Philos. Trans. R. Soc. Lond. Ser. B Biol. Sci. 364, 357-367.

Song, I., and Huganir, R. L. (2002). Regulation of AMPA receptors during synaptic plasticity. Trends Neurosci. 25, 578-588.

Titulaer, M. N., and Ghijsen, W. E. (1997). Synaptoneurosomes. A preparation for studying subhippocampal GABAA receptor activity. Methods. Mol. Biol. 72, 49-59.

Turrigiano, G. G., and Nelson, S. B. (2004). Homeostatic plasticity in the developing nervous system. Nat. Rev. Neurosci. 5, 97-1007.

Volk, L., Kim, C. H., Takamiya, K., Yu, Y., and Huganir, R. L. (2010) Developmental regulation of protein interacting with $\mathrm{C}$ kinase 1 (PICK1) function in hippocampal synaptic plasticity and learning. Proc. Natl. Acad. Sci. U.S.A. 107, 21784-21789.

Yoon, B. J., Smith, G. B., Heynen, A. J., Neve, R. L., and Bear, M. F. (2009). Essential role for a long-term depression mechanism in ocular dominance plasticity. Proc. Natl. Acad. Sci. U.S.A. 106, 9860-9865.

Conflict of Interest Statement: The authors declare that the research was conducted in the absence of any commercial or financial relationships that could be construed as a potential conflict of interest.

Received: 20 March 2012; accepted: 30 April 2012; published online: 16 May 2012.

Citation: Murphy KM, Tcharnaia L, Beshara SP and Jones DG (2012) Cortical development of AMPA receptor trafficking proteins. Front. Mol. Neurosci. 5:65. doi: 10.3389/fnmol. 2012.00065

Copyright (c) 2012 Murphy, Tcharnaia, Beshara and Jones. This is an openaccess article distributed under the terms of the Creative Commons Attribution Non Commercial License, which permits non-commercial use, distribution, and reproduction in other forums, provided the original authors and source are credited. 